\title{
Global Climate Change and the
} Equity-Efficiency Puzzle

\author{
Alan S. Manne \\ Gunter Stephan
}

03-06

April 2003

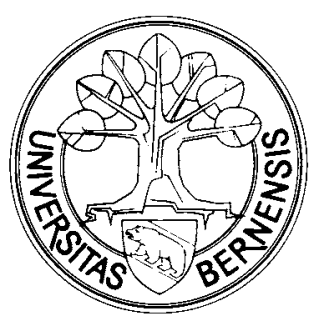

Universität Bern

Volkswirtschaftliches Institut

Gesellschaftstrasse 49

3012 Bern, Switzerland

Tel: 41 (0)31 6314506

Web: www.vwi.unibe.ch 


\title{
GLOBAL CLIMATE CHANGE AND THE EQUITY- EFFICIENCY PUZZLE
}

\author{
By \\ Alan S. Manne and Gunter Stephan \\ Stanford University \\ Institute of Applied Micro-Economics \\ University of Bern
}

Gesellschaftsstrasse $49 \quad \mathrm{CH} 3012$ Bern

Email: gunter.stephan@vwi.unibe.ch

\begin{abstract}
:
There is a broad consensus that the costs of abatement of global climate change can be reduced efficiently through the assignment of quota rights, and through international trade in these rights. But there is no consensus on whether the initial assignment of emission permits can affect the Pareto-optimal global level of abatement.

This paper provides some insight into the equity-efficiency puzzle. Qualitative results are obtained from a small-scale model, and then quantitative evidence of separability is obtained from MERGE, a multi-region integrated assessment model. It is shown that if all the costs of climate change can be expressed in terms of GDP losses, Pareto-efficient abatement strategies are independent of the initial allocation of emission rights. This is the case sometimes described as "market damages".

If, however, different regions assign different values to non-market damages such as species losses, different sharing rules may affect the Pareto-optimal level of greenhouse gas abatement. Separability may then be demonstrated only in specific cases (e.g. identical welfare functions or quasi-linearity of preferences or small shares of wealth devoted to abatement).
\end{abstract}




\section{Introduction}

Global climate change is a public good problem. Rich and poor, all live in the same greenhouse. It is easy to agree on strategies under which everybody will gain. But since it is expected that we need to proceed beyond no regret policies, there must be some arrangement for abatement and burden-sharing. Economic efficiency ensures the maximum potential for each participant to gain from such an agreement. This explains why efficiency, both in terms of cost-effectiveness and Pareto-efficiency, is a major issue in global climate policy.

Standard analysis suggests that the external effects of global climate change can be internalized efficiently through international trade in emission permits (see Rose and Stevens 2000). To see the rationale behind this statement, suppose for a moment that transaction costs are negligible and that information is symmetrically distributed among parties. Then the Theorem of Coase (see Coase 1960) states that if trade of the externality can occur, bargaining will lead to an efficient outcome no matter how property rights are allocated. Or, since trade is a particular type of bargaining: once caps on emission rights are assigned to the individual regions, trading these rights on open international markets has the potential to let all gain from greenhouse gas abatement.

Efficiency in greenhouse gas abatement might be suggested by the Coase Theorem, but it is an open question how to place a certain Pareto-optimum into the framework of a decentralized market-economy without major changes in the allocation of conventional resources. Why? Typically, the outcome of the bargaining process depends on the initial distribution of wealth. In other words, greenhouse gas abatement will depend both on the initial allocation of emission permits and the initial allocation of conventional resources. This explains why some economists insist that the global climate problem cannot be solved without substantial international wealth transfers (see Chichilnisky and Heal 1994). Some even argue that permit trade will lead to large distributional effects (see McKibbin et al. 1999) or - because of terms of trade effects - reduces welfare and increases global pollution (see Copeland and Taylor 2001).

And it explains why the developing countries have invoked equity considerations to justify their strong opposition to cap-and-trade systems. They may be willing to accept clean development mechanisms for individual projects, but seem unwilling to 
couple these mechanisms with any limitations on their overall emission rights. Or to phrase it differently: Because of equity considerations there is strong opposition to efficient solutions of the global climate problem through emission trading.

But what if the Pareto-efficient stock of atmospheric carbon were virtually independent of the initial allocation of conventional resources? Then it should be feasible to separate the equity conflict (who gets what?) from the issue of efficiency. The allocation of shares of the global total would not affect global emissions, but it would affect the quantities of resources available for consumption in each region. Therefore, equity could be based on allocating emission shares to individual nations, and efficiency could be achieved through trading these rights internationally without major changes in the historical ownership of labor, capital and other conventional resources.

As Manne (1999) has formulated the issue, this could have far reaching policy implications. A sharp distinction could then be drawn between determining the global level of abatement and negotiating the cost sharing rules. For example, a credible international agency could set and implement Pareto-optimal global emission targets. Thereafter, emission rights could be assigned to each region through international negotiations. This would not be an easy task, and it would depend upon the skill of the international negotiators. But it would be less complicated than negotiating simultaneously about wealth transfers, the initial allocation of emission rights and emission reduction targets. This explains why it is of more than pure academic interest if we can clarify the equity-efficiency puzzle.

Now, the Coase Theorem not only formulates conditions that assure Paretoefficiency through voluntary cooperation. It also states conditions under which it is feasible to separate the issue of efficiency from that of equity: If, for example, each region's willingness-to-pay for a public good is independent of its level of income, then the optimal quantity of the public good is uniquely determined.

Unfortunately, this result is of only limited help for analyzing the equity-efficiency puzzle in global climate change. There are at least two reasons. First, it is an empirical fact that the willingness-to-pay for environmental protection depends strongly on income and wealth. Typically, the poor inhabitant of a developing country and the welloff person from an industrialized country will differ with respect to their willingness to pay for greenhouse gas abatement. 
Second, climate change is not only a matter of environmental awareness. Climate change might impose high costs on society, and these costs can, in principle, be expressed in terms of GDP losses. This is sometimes termed market damages. In the case of agriculture and forestry, for example, there are market prices by which we can measure the value of output losses. By contrast, there are no market prices for valuing non-market damages such as species losses and catastrophic changes in the ocean currents.

If we are to follow a logical policy, we must balance the economic costs of abating greenhouse gas emissions against the potential benefits from slowing climate change. This explains, why in the model formulations proposed by Nordhaus (1991) and others, the benefits of abatement enter directly into the economy-wide production functions. But a thorough analysis of the issue of separability between equity and efficiency in greenhouse gas abatement must take account not only of market damages but also of the non-market effects of global climate change.

In this paper, we provide two ways of obtaining some insight into the equity-efficiency puzzle. First, we consider a small-scale and then a large-scale model of integrated assessment. Section 2 presents a simple model of a world economy that consists of several countries or regions. In each country welfare depends on the consumption of a public good and a private good. Greenhouse gases are a by-product of the consumption of the private good, and each country can contribute to the public good by investing some of the private good into an abatement technology. In the case of this small-scale model, one can obtain qualitative results. Section 3 presents results from MERGE, a detailed integrated assessment model. Here, it is possible to obtain quantitative evidence of separability.

\section{Separability - a simple analytical treatment}

To clarify ideas, let us consider a simple model of the world economy, where $\mathrm{R}$ regions cooperate in the solution of the global climate problem. There are two commodities, a private one and a public good. The private good is traded on open international markets and can be consumed or invested in greenhouse gas abatement. The public good corresponds to the quality of the world's atmosphere. This could, for example, be measured as the excess of the business-as-usual level over the controlled level of the atmosphere's carbon dioxide concentration. Therefore, the 
amount, $Q$, of the public good depends upon the regions' individual contributions to greenhouse gas abatement. This allows us to sidestep a detailed energy-abatement model by considering the following reduced-form relationship:

$$
Q=\sum_{r} a_{r},
$$

where $a_{r}$ is the quantity of greenhouse gas abatement carried out by region $r$.

Global climate change will affect both regional welfare and the regions' ability to produce. However, let us analyze these two effects separately. First we consider the case in which the public good only affects the regions' ability to produce private goods, net of market damages. Later, we will consider the case in which the public good also affects the utility function directly. This is what we shall mean by nonmarket damages.

\subsection{Abatement benefits affect net production only}

We are interested in cooperative solutions of the global climate problem. For that purpose, we employ Negishi weights to characterize the international market equilibrium. These weights will depend upon the initial endowments of private goods - and the eventual assignment of emission rights and their prices. For the most part, we will consider the special case in which the utility functions are homothetic. In this case, we can interpret the equilibrium Negishi weights as the fractions of the world's wealth that are owned by each region. See Rutherford (1999).

Now, let $\omega_{r}>0, r=1, \ldots, R$, be the Negishi weights associated with region $r$, and let $y_{r}$ be the fraction of the world's conventional wealth that is available to region $r$. Each region's welfare may be measured by a continuous, strictly monotonous and strictly quasi-concave utility function, $\mathrm{U}_{\mathrm{r}}$. And since market damages are the only consideration here, $U_{r}$ depends only on the consumption of the private good, $c_{r}$. Then for a Pareto-optimal solution, the expression

$$
\sum_{r} \omega_{r} U_{r}\left[c_{r}\right]
$$


is maximized subject to the constraint (2.1) and

$$
\sum \Phi_{r}(Q)_{r} y_{r}-\sum_{r} c_{r}-\sum_{r} g_{r}\left(a_{r}\right)=0
$$

Equation (2.2) shows how the benefits from abatement affect the regional provision of the private good. $\Phi_{\mathrm{r}}$ may be called the region-specific environmental availability factor. That is, the higher the overall atmospheric quality $Q$, the higher is the fraction $\Phi_{r}(Q)$ of conventional wealth that is available to region $r$. Alternatively, $1-\operatorname{Sr}(Q)$ measures the economic costs of global climate change in terms of foregone GDP. Therefore, $\sum \Phi_{\mathrm{r}}(\mathrm{Q})_{\mathrm{r}} \mathrm{y}_{\mathrm{r}}$ is called the global green GDP, and (2.2) describes how the world's green GDP is allocated between consumption and abatement, where $g_{r}$ is the regional abatement cost function.

Let us suppose that there are increasing marginal costs of abatement, $g_{r}^{\prime}>0, g^{\prime \prime}{ }_{r}>0$, and decreasing benefits from abatement, $\Phi_{r}^{\prime}>0, \Phi^{\prime \prime}{ }_{r}<0$. Furthermore, let us focus on the case where the public good is provided at positive levels, and where positive amounts of the private good are consumed. Then first order conditions imply the following optimality conditions for each region $r$ :

$$
\begin{aligned}
& \omega_{r} \partial U_{r} / \partial c_{r}=p \\
& \operatorname{pg}_{r}^{\prime}\left(a_{r}\right)=p\left[\sum_{j=1, \ldots, R} \Phi_{j}^{\prime}(Q) y_{j}\right]
\end{aligned}
$$

where $\pi$, and $p$ are the Lagrange-multipliers that are associated with equations (2.1) and (2.2), respectively.

Since prices are positive, (2.4) implies that regardless of the values of the Negishi weights, the amount of abatement is the same. Intuitively this is explained by the fact that the optimal abatement is the one that maximizes $\sum_{r} c_{r}$. (Recall condition (2.2).) In other words, we minimize market damages plus abatement costs in order to obtain maximal aggregate consumption.

Formally, separability results from a one-sentence proof. Let us assume for a moment that $Q$ and $Q^{*}$ are two different Pareto-efficient levels of atmospheric quality, 
with $Q<Q^{*}$. Let $c_{r}$ and $c_{r}^{*}, r=1, \ldots, R$, denote the optimal private consumption vectors associated with $Q$ and $Q^{*}$, respectively. Similarly, let $a_{r}$ and $a_{r}{ }^{*}, r=1, \ldots R$, be the Pareto-efficient abatement vector associated with $Q$ and $Q^{*}$. Since there are decreasing benefits from abatement, $\Phi_{j}^{\prime}(Q)>\Phi_{j}^{\prime}\left(Q^{*}\right)$ for all $j=1, \ldots, R$. Therefore, from (2.4) it follows that: $g_{r}^{\prime}\left(a_{r}\right)>g_{r}^{\prime}\left(a_{r}^{*}\right)$. And since $g_{r}^{\prime}>0, g^{\prime \prime}{ }_{r}>0$, this in turn means that $g_{r}\left(a_{r}\right)>g_{r}\left(a_{r}^{*}\right)$ for all regions $r$. Hence,

$$
\sum_{r} c_{r}=\sum \Phi_{r}(Q)_{r} y_{r}-\sum_{r} g_{r}\left(a_{r}\right)<\sum \Phi_{r}\left(Q^{*}\right)_{r} y_{r}-\sum_{r} g_{r}\left(a_{r}^{*}\right)=\sum_{r} c_{r}^{*}
$$

This contradicts the assumption that $\left(Q, C_{1}, \ldots, C_{R}\right)$ is Pareto-efficient.

Indeed, we have shown a bit more than required. Our reasoning implies that the Pareto-efficient provision of the public good is uniquely determined. Hence, independent of the distribution of conventional wealth and of carbon rights, there is only one optimal vector of global greenhouse gas abatement. Moreover, this conclusion can be generalized to a case with multiple time periods, provided that the marginal productivity of capital remains fixed over time.

\subsection{Abatement benefits affect both utilities and production}

Now suppose that global climate change directly affects regional production and utilities. This means that the public good enters into the objective function. Hence, the regional welfare, $U_{r}, r=1, \ldots, R$, in the following not only depends on the consumption of the private good, $c_{r}$, but also on that of the public good, $Q$, with $\partial U_{r} / \partial Q>0$.

Given this, the global Negishi maximand is written

$$
\sum_{r} \omega_{r} U_{r}\left[c_{r}, Q\right]
$$

Again this is to be maximized subject to the constraints (2.1) and (2.2). As above we focus on the case that both the private and the public good are provided at positive levels. Then first order condition (2.4) changes to 


$$
\operatorname{pg}_{r}^{\prime}\left(a_{r}\right)=p\left[\sum_{j=1, \ldots, R} \Phi_{j}^{\prime}(Q) y_{j}\right]+\sum_{j=1, \ldots, R} \omega_{j} \frac{\partial U_{j}}{\partial Q}
$$

Obviously, the Pareto-efficient internalization of the global climate effect now depends on two effects (compare conditions (2.4) and (2.4a)): on the aggregated losses in conventional wealth due to climate change as so far, and on the aggregated willingness to pay for protecting the global climate in addition. The Pareto-efficient provision of the public good therefore depends upon the Negishi weights.

What can be learned from this? Recall that if the utility functions are homothetic, then the Negishi weights may be interpreted as each region's share in the ownership of the world's resources. These weights are determined so as to be proportional to each region's wealth available for expenditure on private and public goods. In other words, if the exogenously determined regional shares in the value of the public good are denoted by the parameter $\sigma_{r}, r=1, \ldots, R$, then the Negishi weight $\omega_{r}$ of region $r$ will be proportional to

$$
\mathrm{p} \Phi_{\mathrm{r}}(\mathrm{Q})_{\mathrm{r}} \mathrm{y}_{\mathrm{r}}-\pi\left(\sigma_{\mathrm{r}} \mathrm{Q}-\mathrm{a}_{\mathrm{r}}\right)
$$

where $\pi$ is the shadow price of the quality of the atmosphere. (Recall (2.1).) The last parenthesis of (2.6) indicates the difference between the region's share in global abatement obligations, $\sigma_{\mathrm{r}} \mathrm{Q}$, and its actual abatement level, $\mathrm{a}_{\mathrm{r}}$. This quantity may be positive or negative depending on whether emission rights are bought or sold on the international market.

Given these circumstances, we cannot expect that the optimal provision of the public good will in general be independent of the initial allocation of emission rights. To see this, suppose that regions differ with respect to their willingness to pay for atmospheric quality. Suppose further that emission rights are redistributed from regions with high willingness to regions with low willingness to pay for greenhouse gas abatement. As (2.6) indicates, changing the assignments of emission rights in this way implies a redistribution of wealth. Regions which are characterized by low willingness to pay for atmospheric quality will become richer, hence will be assigned 
higher Negishi weights. This changes the last term in the right hand side of equation (2.4a) and therefore affects optimal greenhouse gas abatement.

This observation leads to the question: Can conditions be identified under which the Pareto-efficient stock of atmospheric carbon is independent of the initial distribution of emission shares? Condition (2.4a) suggests that we might search in two different directions: (1) for conditions which ensure that prices and Negishi weights remain (almost) unchanged, and (2) for conditions which ensure that the society's aggregated willingness to protect the world climate remains unaffected if the initial assignment of carbon rights is reallocated from one region to another.

Note that there is an important difference between these two types of separability conditions. Invariance of prices and Negishi weights depends very much upon numerical values, hence the order of magnitude by which the assignment of carbon rights influences the regions' income. This will be discussed in more detail in a general integrated assessment model (see Section 3.3). Here we will focus on structural conditions under which global greenhouse gas abatement is independent of the initial distribution of emission rights. To this end consider an instructive example. Suppose that regions are characterized by Cobb-Douglas welfare functions, $U_{r}=\alpha_{r} l n c_{r}+\beta_{r} \ln Q$. If the elasticity of welfare with respect to the public good, $\beta_{r}$, is (almost) identical across regions, then $(2.4 a)$ will simplify to

$$
\operatorname{pg}^{\prime}{ }_{r}\left(a_{r}\right)=p\left[\sum_{j=1, \ldots, R} \Phi_{j}^{\prime}(Q) y_{j}\right]+\beta Q^{-1}\left[\sum_{j=1, \ldots, R} \omega_{j}\right]
$$

Since Negishi weights sum up to unity, the right hand side of (2.4b) is independent of the specific values of the Negishi weights, and the arguments from Section 2.1 directly apply.

In other words, separability in optimal greenhouse gas abatement is observed if the willingness to pay for greenhouse gas abatement is almost identical across regions. There is, however, a further interpretation. Aggregated willingness to pay is independent of the distribution of income. This becomes more obvious through rearranging terms in condition (2.4a). Then we obtain for each region $r$ 


$$
g_{r}^{\prime}\left(a_{r}\right)-\left[\sum_{j=1, \ldots, R} \Phi_{j}^{\prime}(Q) y_{j}\right]=\sum_{j=1, \ldots, R}\left[\frac{\partial U_{j}}{\partial Q} / \frac{\partial U j}{\partial c j}\right]
$$

Since the marginal costs of abatement are identical across regions, (2.7) is nothing else than a variant of the well-known optimality condition for public goods: The sum of regional benefits from the public good (right hand side of (2.7) has to be equal to its total marginal costs (see the left hand side of (2.7)). Again (see Section 2.1) Pareto-efficiency will be obtained, if we minimize market damages plus abatement costs and simultaneously maximize aggregate consumption. And if the solution to this optimization problem is unique, then there is separability in optimal greenhouse gas abatement. Or to phrase it differently: Aggregated willingness to pay for the global climate attains a maximum at the Pareto-efficient stock of atmospheric carbon. Formally, this can be expressed as follows: For any pair of Pareto-efficient levels of atmospheric quality $Q$ and $Q^{*}$ :

$$
\mathrm{Q}^{*}>\mathrm{Q} \text { implies } \quad \sum_{\mathrm{j}=1, \ldots, \mathrm{R}}\left[\frac{\partial \mathrm{Uj}}{\partial \mathrm{Q}^{*}} / \frac{\partial \mathrm{Uj}}{\partial \mathrm{cj}^{*}}\right] \leq \sum_{\mathrm{j}=1, \ldots, \mathrm{R}}\left[\frac{\partial \mathrm{Uj}}{\partial \mathrm{Q}} / \frac{\partial \mathrm{Uj}}{\partial \mathrm{cj}}\right]
$$

where $\mathrm{C}_{\mathrm{j}}^{*}$ is the optimal consumption associated to $\mathrm{Q}^{*}$. By repeating the arguments from Section 2.1, we can again show by contradiction that the optimal level of the public good is uniquely determined. (For a proof see the Appendix.)

What conclusions can be drawn from our considerations so far? One is that equityefficiency separability occurs if the regions' welfare functions are not homothetic, but are quasi-linear with respect to the internationally traded private good. That is, the individual utility functions consist of a linear term in $c_{r}$ plus a nonlinear term, $V_{r}(Q)$. That is, $U_{r}\left[c_{r}, Q\right]=c_{r}+v_{r}(Q)$. Now, if $v_{r}^{\prime}>0$ and $v^{\prime \prime}{ }_{r}<0, Q^{*}>Q$ immediately implies $\left[\sum_{j=1, \ldots, R} \vee_{j}^{\prime}\left(Q^{*}\right)\right]<\left[\sum_{j=1, \ldots, R} \vee_{j}^{\prime}(Q)\right]$, and separability follows.

Another way to interpret this is that separability is a satisfactory approximation if the distribution of emission rights leads to only small changes in real income. This is indeed what we seem to find in the case of the large-scale numerical model known as MERGE. 


\section{The MERGE Model}

The following analysis is based on MERGE (a model for evaluating the regional and global effects of greenhouse gas reduction policies). MERGE is an intertemporal general equilibrium model. Like its predecessors, the version used for the present analysis is designed to be sufficiently transparent so that one can explore the implications of alternative viewpoints in the greenhouse debate. It integrates submodels that provide a reduced-form description of the energy sector, the economy, emissions, concentrations, temperature change and damage assessment.

\subsection{A short model overview}

MERGE combines a bottom-up representation of the energy supply sector together with a top-down perspective on the remainder of the economy. For a particular scenario, a choice is made among specific activities for the generation of electricity and for the production of non-electric energy. Oil, gas and coal are viewed as exhaustible resources. There are introduction constraints on new technologies and decline constraints on existing technologies. MERGE also provides for endogenous technology diffusion. That is, the near- term adoption of high-cost carbon-free technologies in the electricity sector leads to accelerated future introduction of lower cost versions of these technologies.

Outside the energy sector, the economy is modeled through nested constant elasticity production functions. The production functions determine how aggregate economic output depends upon the inputs of capital, labor, electric and non-electric energy. In this way, the model allows for both price-induced and autonomous (nonprice) energy conservation and for interfuel substitution. It also allows for macroeconomic feedbacks. Higher energy and/or environmental costs will lead to fewer resources available for current consumption and for investment in the accumulation of capital stocks. Economic values are reported in U.S. dollars of constant 2000 purchasing power.

The world is divided into nine regions: 1) the USA, 2) WEUR (Western Europe), 3) Japan, 4) CANZ (Canada, Australia and New Zealand), 5) EEFSU (Eastern Europe and the Former Soviet Union), 6) China, 7) India, 8) MOPEC (Mexico and OPEC) and, 9) ROW (the rest of world). Under the Kyoto Protocol, the first five of these re- 
gions constitute "Annex B". The others are known as developing countries, and they have high rates of population growth. Time periods are each a decade in length, and the horizon extends through 2150. In order to minimize horizon effects, results are typically reported only through 2100 . At this level of aggregation, the model contains about 20,000 decision variables and 18,000 constraints - excluding the upper and lower bounds on individual variables. With a hot start, the run time seldom exceeds half an hour on a $1000 \mathrm{mHz}$ desktop computer.

Each region is represented by a single long-lived agent, and each of the agents maximizes the discounted utility of its consumption subject to an intertemporal budget constraint. Each region's wealth includes not only capital, labor and exhaustible resources, but also its negotiated international shares in emission rights. Particularly relevant for the present calculations, MERGE provides a general equilibrium formulation of the global economy. We model international trade in emission rights, allowing regions with high marginal abatement costs to purchase emission rights from regions with low marginal abatement costs. There is also trade in oil, gas and energyintensive goods. International capital flows are endogenous. A region may have a positive or negative trade surplus in any one time period, but the present value of these surpluses must balance off to zero over the entire planning horizon.

MERGE can be used for either cost-effectiveness or cost-benefit analysis. For the latter purpose (the application presented here), the model translates global warming into its market and non-market impacts. Market effects are intended to measure direct impacts on the GDP, e.g., agricultural products and timber. Non-market effects refer to those not traditionally included in the national income accounts, e.g., the impacts on biodiversity, environmental quality and human health. These effects are probably more important than market effects - and they are even more difficult to measure.

For Pareto-optimal outcomes, i.e., those scenarios in which the costs of abatement are balanced against the impacts of global climate change, each region evaluates its future welfare by adjusting the value of its consumption for both the market and nonmarket impacts of climate change. The market impacts represent a direct claim on gross economic output -- along with energy costs, aggregate consumption and investment. Non-market impacts enter into each region's intertemporal utility function, and are viewed as an adjustment to the conventional value of macroeconomic consumption. There is a greater than unitary per capita income elasticity of demand for 
abating non-market damages. For more on the model, see our web site: http://www.stanford.edu/group/MERGE/.

\subsection{Simulation results}

To illustrate the separability of equity and efficiency, we will consider three different rules for the assignment of emission rights and show that these all lead to more or less the same Negishi weights - and therefore very similar levels of emissions and marginal costs of abatement. This illustration will be based on the following three alternatives:

- rights assigned in proportion to initial population - an egalitarian principle;

- rights assigned in proportion to initial emissions during the early years, and then a transition (by 2050) to an assignment in proportion to the population - a pragmatic principle, the one typically employed in MERGE; and

- rights assigned in proportion to initial emissions - a grandfathering principle.

Figure 1 compares a business-as-usual (no abatement) carbon emissions scenario with each of these three alternatives. Note that the three are indistinguishable. Similarly, Figure 2 compares the three sets of prices of tradeable carbon emission permits. Again, the different burden-sharing rules lead to an indistinguishable set of efficiency prices. Similar results have been obtained in all experiments with MERGE provided that there is free trade in emission rights.

In order to understand this result, it is instructive to examine the Negishi weights shown in Table 1. Clearly, grandfathering is favorable to the five Annex B nations, and the population criterion is favorable to the four developing regions. However, all three sharing rules lead to weights that are identical to three decimal digits. In order to detect differences, it is necessary to go to six digits. Consider the ratio of the weights implied by the egalitarian rule to that implied by grandfathering. There is only one region (India) for which this ratio differs from unity by more than $1 \%$. That is, the initial endowments of capital, labor and exhaustible resources are the principal 
determinants of the Negishi weights. These far outweigh the importance of the value of each region's share in emission rights.

Table 1.. Negishi weights under alternative sharing rules

\begin{tabular}{||l|c|c|c|c||}
\hline ESA & EGALITARIAN & PRAGMATIC & GRANDFATHERING & $\begin{array}{l}\text { EGALITARIAN/ } \\
\text { GRANDFATHERING }\end{array}$ \\
\hline WEUR & 0.224516 & 0.224759 & 0.225367 & 0.996 \\
\hline JAPAN & 0.089233 & 0.089272 & 0.089370 & 0.998 \\
\hline CANZ & 0.032243 & 0.032280 & 0.032371 & 0.998 \\
\hline EEFSU & 0.044120 & 0.044191 & 0.044370 & 0.994 \\
\hline CHINA & 0.094155 & 0.094065 & 0.093837 & 1.003 \\
\hline INDIA & 0.044032 & 0.043879 & 0.043492 & 1.012 \\
\hline MOPEC & 0.047114 & 0.047117 & 0.047130 & 1.000 \\
\hline ROW & 0.198962 & 0.198700 & 0.198041 & 1.005 \\
\hline TOTAL & 1.000000 & 1.000001 & 1.000000 & \\
\hline \hline
\end{tabular}


Figure 1. Global carbon emissions

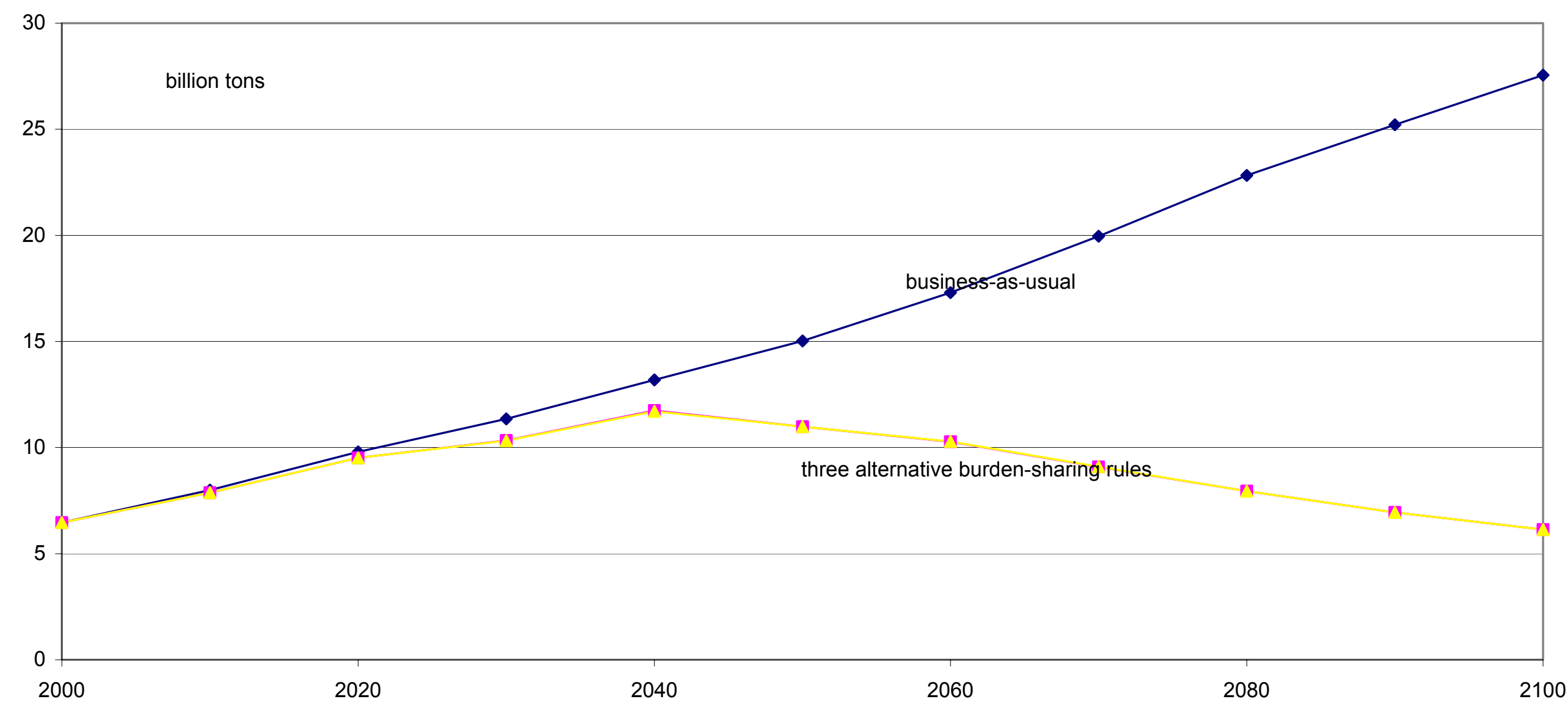


Figure 2. Value of tradeable carbon emission permits

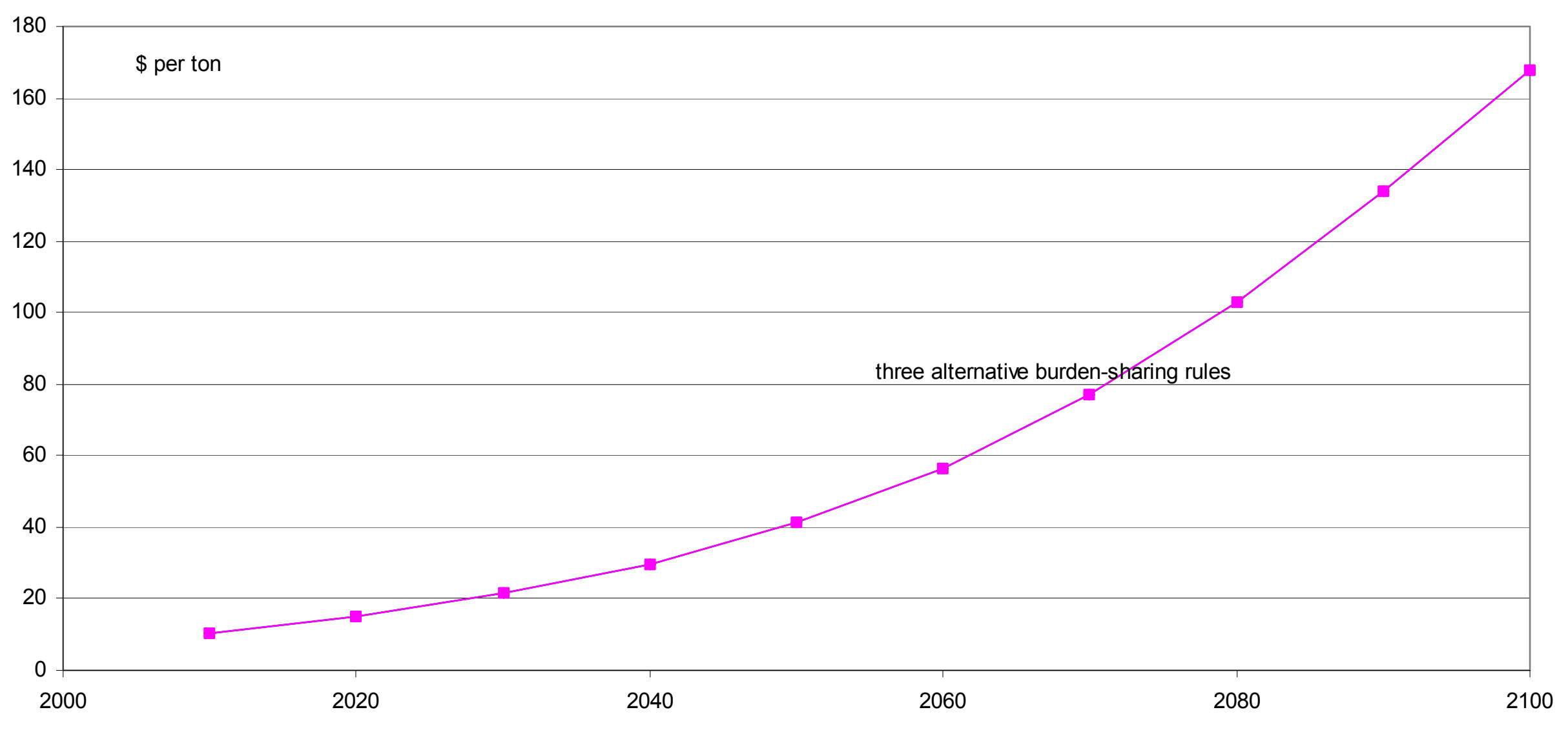




\section{References}

Chichilnisky, G. and Heal, G. (1994), "Who should abate carbon emissions? An international viewpoint", Economic Letters 44:443-449.

Coase, R. (1960), "The problem of social cost", Journal of Law and Economics 3:144.

Copeland, B. and Taylor, M. (2001), Free trade and global warming: A trade theory view on the Kyoto protocol, mimeo, University of Wisconsin-Madison.

Manne, A. (1999), "Equity, efficiency and discounting", in: Discounting and Intergenerational Equity (P. Portney and J. Weyant eds.), Resources for the Future, Washington D.C.

Manne, A., Mendelsohn, R. and Richels R.. (1995), "MERGE: a model for evaluating regional and global effects of GHG reduction policies", Energy Policy 3:1.

McKibbin, W., Shackleton, R. and Wilcoxen, P. (1999), "What to expect from an international system of tradable permits for carbon emissions", Resource and Energy Economics 9:319-346.

Nordhaus, W. (1991), "To Slow or not to Slow: The Economics of the Greenhouse Effect", The Economic Journal 101:920-937.

Rutherford, T. (1999), "Sequential joint maximization", in: Energy and Environmental Policy Modeling (J. Weyant ed.), Kluwer, Dordrecht. 


\section{Appendix}

Let the regional utility functions $U_{r}\left[c_{r}, Q\right], r=1, \ldots R$, be strictly increasing in the consumption of the private good, $\partial U_{r} / \partial c_{r}>0$, as well as the public one, $\partial U_{r} / \partial Q>0$. Suppose further that there are increasing marginal costs of abatement, $g_{r}^{\prime}>0$, $g^{\prime \prime}{ }_{r}>0$, and decreasing benefits from abatement, $\Phi_{r}^{\prime}>0, \Phi^{\prime \prime}{ }_{r}<0$. The Paretoefficient level of atmospheric carbon $Q$ is independent of the initial distribution of conventional wealth if

(2.8) $\quad \sum_{\mathrm{j}=1, \ldots, \mathrm{R}}\left[\frac{\partial \mathrm{Uj}}{\partial \mathrm{Q}^{*}} / \frac{\partial \mathrm{Uj}_{\mathrm{j}}}{\partial \mathrm{cj}^{*}}\right] \leq \sum_{\mathrm{j}=1, \ldots, \mathrm{R}}\left[\frac{\partial \mathrm{Uj}}{\partial \mathrm{Q}} / \frac{\partial \mathrm{Uj}}{\partial \mathrm{cj}}\right]$ for any $\mathrm{Q}^{*}>\mathrm{Q}$.

\section{Proof (by contradiction)}

Let condition (2.8) is fulfilled and suppose that $\left(\mathrm{Q}, \mathrm{C}_{1}, \ldots, \mathrm{C}_{\mathrm{R}}\right)$ and $\left(\mathrm{Q}^{*}, \mathrm{C}_{1}{ }^{*}, \ldots, \mathrm{C}_{\mathrm{R}}{ }^{*}\right)$ are two different Pareto-efficient allocations with $Q^{*}>Q$. Given the assumptions imposes upon $\mathrm{gr}_{\mathrm{r}}$ and $\Phi_{\mathrm{r}}$, optimality condition (2.7) obviously implies for any region $\mathrm{r}$

$$
g_{r}^{\prime}\left(a_{r}^{*}\right)<g_{r}^{\prime}\left(a_{r}\right)
$$

hence $g_{r}\left(a_{r}{ }^{*}\right)<g_{r}\left(a_{r}\right)$ for all r. Therefore we get from the material balance (2.2)

$$
\sum_{r} c_{r}=\sum \Phi_{r}(Q)_{r} y_{r}-\sum_{r} g_{r}\left(a_{r}\right)<\sum \Phi_{r}\left(Q^{*}\right)_{r} y_{r}-\sum_{r} g_{r}\left(a_{r}{ }^{*}\right)=\sum_{r} c_{r}^{*}
$$

which contradicts the assumption that $\left(Q, C_{1}, \ldots, C_{R}\right)$ is Pareto-efficient. 